\title{
Systemic Delivery of Parathyroid Hormone (1-34) Using Inhalation Dry Powders in Rats
}

\author{
VALÉRIE CODRONS, ${ }^{1}$ FRANCIS VANDERBIST, ${ }^{2}$ ROGER K. VERBEECK, ${ }^{3}$ MOHAMMED ARRAS, ${ }^{4}$ DOMINIQUE LISON, ${ }^{4}$ \\ VÉRONIQUE PRÉAT, ${ }^{1}$ RITA VANBEVER ${ }^{1}$ \\ ${ }^{1}$ Université catholique de Louvain, School of Pharmacy, Department of Pharmaceutical Technology, Avenue E. Mounier, \\ 73 UCL 73.20-1200 Brussels, Belgium \\ ${ }^{2}$ Laboratoires SMB, Pharmaceutical Research and Development, Brussels, Belgium \\ ${ }^{3}$ Université catholique de Louvain, School of Pharmacy, Unité de Pharmacocinétique, Métabolisme, Nutrition et Toxicologie, \\ Brussels, Belgium \\ ${ }^{4}$ Université catholique de Louvain, School of Public Health, Industrial Toxicology and Occupational Medicine Unit, \\ Brussels, Belgium
}

Received 18 July 2002; revised 21 October 2002; accepted 6 November 2002

\begin{abstract}
The aim of this work was to prepare and characterize inhalation dry powders of human parathyroid hormone (PTH), as well as to assess their efficacy for systemic delivery of the peptide and safety in rats. The powders were prepared by spray-drying using PTH, sugars, dipalmitoylphosphatidylcholine, and/or albumin. They presented an average primary particle diameter of $4.5 \mu \mathrm{m}$ and tap density of $0.06 \mathrm{~g} / \mathrm{cm}^{3}$, a mass median aerodynamic diameter between 3.9 and $5.9 \mu \mathrm{m}$, and reached up to $98 \%$ emitted dose and up to $61 \%$ fine particle fraction in the multi-stage liquid impinger using a Spinhaler inhaler device. Varying the airflow rate from 30 to $100 \mathrm{~L} / \mathrm{min}$ had limited influence on the aerodynamic behavior of the aerosols. The absolute PTH bioavailability was $21 \%$ after intratracheal administration of the powder formed of PTH/albumin/ lactose/dipalmitoylphosphatidylcholine and $18 \%$ after subcutaneous injection in rats. Equilibrium dialysis revealed a $78 \%$ binding of PTH to albumin and the withdrawal of albumin from the powder increased absolute bioavailability after inhalation from 21 to $34 \%$. No acute inflammation appeared in the lung up to $48 \mathrm{~h}$ after a single inhalation. The increased bioavailability of the optimized powder aerosol of PTH makes it a promising alternative to subcutaneous injection. (C) 2003 Wiley-Liss, Inc. and the American Pharmaceutical Association J Pharm Sci 92:938-950, 2003
\end{abstract}

Keywords: pulmonary drug delivery; inhalation dry powder; peptide delivery; human parathyroid hormone; protein binding; bioavailability

\section{INTRODUCTION}

Osteoporosis is a metabolic bone disease characterized by low bone mass and structural deterioration of bone tissue leading to increased risks of fracture. Antiresorptive agents (e.g., estrogens,

Correspondence to: Rita Vanbever (Telephone 32-2-764-7325; Fax: 32-2-764-73-98; E-mail: vanbever@farg.ucl.ac.be)

Journal of Pharmaceutical Sciences, Vol. 92, 938-950 (2003)

() 2003 Wiley-Liss, Inc. and the American Pharmaceutical Association bisphosphonates, calcitonin) reduce bone remodeling by inhibiting osteoclasts, and thereby prevent further bone loss. However, the architecture and the mass of the bone remain unchanged. A more effective therapeutic approach would involve the stimulation of new bone formation. Anabolic effect on bone has been demonstrated after the intermittent subcutaneous (sc) administration of low doses of parathyroid hormone. Parathyroid hormone stimulates new cortical and trabecular bone formation, improves bone 
growth and density. Its 1 to $34 \mathrm{~N}$-terminal fragment (PTH) exhibits full biological activity and has been shown effective for the treatment of postmenopausal osteoporosis in Phase III clinical trials. ${ }^{1,2}$

A major challenge that remains in PTH therapy consists in finding a noninvasive alternative to the daily sc injections. Oral PTH delivery showed a bioavailability of $5 \%$ and $2.1 \%$ relative to sc administration in rats and monkeys, respectively. ${ }^{3}$ The pulmonary route has also been evaluated in rats and monkeys using intratracheal instillation or nebulization and the absolute bioavailabilities were $40 \%$ and $29 \%$, respectively. ${ }^{4,5}$

Systemic delivery of macromolecules by inhalation is attracting considerable attention since a decade because a number of peptides or proteins are more efficiently absorbed from the lung than from the oral, nasal, or transdermal routes. Efficient systemic absorption results from unique physiological features of the lung: the large absorptive surface area, the very thin diffusion path to the bloodstream, the elevated blood flow, the relatively low metabolic activity locally as well as the avoidance of first-pass hepatic metabolism. ${ }^{6}$

Dry powder inhalers present advantages over nebulizers and metered-dose inhalers for the administration of peptide and protein therapeutics to the lung. Dry powder inhalers are portable, easy to operate (breath-actuated), inexpensive, propellant-free, and show improved stability of the formulation as a result of the dry state. ${ }^{7,8}$

The aim of our study was to optimize the systemic delivery of the 1-34 fragment of human parathyroid hormone using inhalation dry powders. We prepared powders with sugars and compounds endogenous to the lung such as albumin and dipalmitoylphosphatidylcholine (DPPC) by spray-drying, and analyzed their aerosolization properties as well as the chemical integrity of the peptide incorporated. We assessed in vivo in the rat the efficacy for systemic absorption of dry powders of PTH made of different composition and examined the tolerability of the rat lung to powder insufflation.

\section{EXPERIMENTAL SECTION}

\section{Chemicals}

The 1-34 fragment of human parathyroid hormone (4118 Da; pI 8.3), referred to as PTH in the remainder of the text, was obtained from UCBBiotechnology (Braine-l'Alleud, Belgium). Human serum albumin (fraction V, 96-99\% albumin, not purified of fatty acids), D-trehalose dihydrate, 96 vol \% ethanol, xylazine, nicotinamide adenine dinucleotide $\left(\mathrm{NAD}^{+}\right)$, and sulforhodamine 101 were obtained from Sigma-Aldrich (Bornem, Belgium). $\alpha$-Lactose monohydrate was purchased from Acros Organics (Fair Lawn, NJ) and DPPC from Lipoid GMBH (Ludwigshafen, Germany). Coumarin-6 was purchased from ICN Biomedicals Inc. (Cleveland, OH). Hank's balanced salt solution (HBSS) was supplied by Life Technologies (Merelbeke, Belgium), formaldehyde, $\mathrm{NaH}_{2} \mathrm{PO}_{4} \cdot 1$ $\mathrm{H}_{2} \mathrm{O}, \mathrm{Na}_{2} \mathrm{HPO}_{4} \cdot 2 \mathrm{H}_{2} \mathrm{O}, \mathrm{NaCl}$, and acetonitrile high-performance liquid chromatography (HPLC) grade by Merck Eurolab (Leuven, Belgium). Sodium pentobarbital, ketamine (Ketalar) and Thalamonal were purchased from Certa (Medeva Pharma, Braine-l'Alleud, Belgium), Warner-Lambert (Zaventem, Belgium), and Janssen-Cilag (Berchem, Belgium), respectively. ([ $\left.\left.{ }^{125} \mathrm{I}\right]-\mathrm{Tyr}^{0}\right)$ hPTH(1-34) was supplied by Bachem (former Peninsula Laboratories, Merseyside, UK).

\section{Animals}

Eleven- to 12 -week-old male Wistar rats $(428 \pm$ $4 \mathrm{~g}$; Iffa Credo, Saint Germain les Arbreles, France) were used for the pharmacokinetic studies and 8- to 10 -week-old male Wistar rats $(373 \pm 10 \mathrm{~g}$; Elevage Janvier, Le Genest St Isle, France) were used for the tolerability studies. Animals had free access to tap water and laboratory diet (pelleted commercial standard diet, no. A04; Usine Alimentation Rationnelle, Epinay-sur-Orge, France) during the experimental period. All experimental protocols in rats were approved by the Ethical Committee for Animal Care and Use of the Faculty of Medicine of the Universite catholique de Louvain.

\section{Formulation of the Dry Powders}

Dry powders were prepared by spray-drying using PTH, human serum albumin, a sugar (lactose or trehalose), DPPC, and/or a fluorescent dye (coumarin-6 or sulforhodamine 101). ${ }^{9,10}$ A fluorescent marker was incorporated in the formulations at a low load $(0.1$ or $0.2 \% \mathrm{w} / \mathrm{w})$, except for the powders administered in vivo, to allow easy quantification of the powder deposited in the impactor stages. The lipophilic dye, coumarin-6, originally used for that purpose, was replaced by sulforhodamine, a hydrophilic molecule because it dissolved more easily in water mixed with ethanol that was used 
in the case of the multi-stage liquid impinger (MSLI, see below). PTH, the sugar, sulforhodamine, and/or albumin were dissolved in $0.5 \mathrm{mM}$ phosphate buffer $\mathrm{pH}$ 7.4. DPPC and coumarin-6 were dissolved in $96 \%$ ethanol. The two solutions were then combined to form a $70 \%$ ethanolic solution of $0.1 \% \mathrm{w} / \mathrm{v}$ total excipients and PTH concentration.

The powders were produced using a LabPlant laboratory-scale spray-dryer (Lab-Plant Ltd., Huddersfield, UK) at low relative humidity (27$35 \%$ ). The solutions were pumped into the drying chamber at a rate of $10 \mathrm{~mL} / \mathrm{min}$ and pneumatically atomized through a two fluids external mixing 0.5 -mm nozzle using compressed air at $0.5 \mathrm{bar}$. The inlet temperature was $100^{\circ} \mathrm{C}$; under these conditions, the outlet temperature varied between $52^{\circ}$ and $62^{\circ} \mathrm{C}$. The powders were collected and stored in a desiccator (at $25 \%$ relative humidity and at room temperature or $4{ }^{\circ} \mathrm{C}$ for the powders containing $\mathrm{PTH}$ ). Yields ranged between 10 and $20 \%{ }^{10}$

\section{Particle Size, Density, and Morphology}

The primary geometric particle diameter $(d)$ was measured by laser diffraction in the wet state mode. ${ }^{11}$ Powder samples were suspended in water in a $50-\mathrm{mL}$ glass cuvette and stirred with a magnetic bar at $1000 \mathrm{rpm}$. Diameter was measured using a laser diffractometer (HELOS; Sympatec $\mathrm{GmbH}$, Clausthal-Zellerfelg, Germany) following a short period of sonication (between $30 \mathrm{~s}$ and $2 \mathrm{~min}$ ) at a power of $60 \mathrm{~W}$ (CUVETTE, Sympatec; 8.5-mm diameter ultrasound tip). An R2 lens allowing measurements in the range of $0.25-$ $87.5 \mu \mathrm{m}$ was used. The particle size analysis was performed using WINDOX 3.4 software and the mass median particle diameter was taken into account. Each measurement was performed in triplicate and was accurate up to the second decimal.

The powder density ( $\rho$ ) was determined by tap density measurements, i.e., following 1000 taps which allowed the density to plateau. ${ }^{12}$ The measurement was highly reproducible (accurate up to the second decimal) and was generally not repeated in order to save dry powders. The primary aerodynamic diameter of the particles, $d_{\mathrm{aer}}$, was calculated based on the following definition ${ }^{13}$ : $d_{\text {aer }}=\sqrt{\frac{\rho}{\rho_{1}}} d$, with $\rho_{1}=1 \mathrm{~g} / \mathrm{cm}^{3}$.

The particles were viewed using a conventional scanning electron microscope (Philips CM12/ STEM, Eindhoven, The Netherlands). The dry powder samples were mounted on metal plates and a 10-nm-thick gold film was sputter coated on the samples with a Balzers SCA 020 (Balzers Union, Liechtenstein) before visualization.

\section{Aerosolization Properties of the Powders In Vitro}

The pulmonary deposition of the dry powders was estimated in vitro using an Andersen cascade impactor equipped with a USP induction port (1 ACFM Eight Stage Non-Viable Cascade Impactor; Graseby Andersen, Atlanta, GA) under controlled relative humidity $(30-40 \%)$, as previously described. ${ }^{10,11}$ The trays of the impactor were coated with a hydroxypropylmethylcellulose gel $(22.5 \% \mathrm{w} / \mathrm{v}$ in water). A hard gelatin capsule (size 2, Capsugel), previously stored in a desiccator for at least 2 days, was half-filled with the powder and placed in a Spinhaler inhaler (Fisons, Bedford, MA). The capsule was then pierced and the liberated powder drawn through the impactor operated at $28.3 \mathrm{~L} / \mathrm{min}$ (the flow rate at which the Andersen impactor is calibrated; flowmeter type GMTX, Platon, Hampshire, UK ) for a period of $10 \mathrm{~s}$, which allowed the aspiration of $4 \mathrm{~L}$ of air through the apparatus, as recommended by pharmacopoeias. ${ }^{14}$ The powder deposited on the different levels was recovered by immersing each tray and the stage below in $80 \%$ ethanol. The powder deposited in the throat and pre-separator was also collected. After dissolution of the particles, the fluorescence of each solution, due to coumarin- 6 or sulforhodamine incorporated in the dry powder, was determined using a PerkinElmer Luminescence Spectrometer LS50B (coumarin: $\lambda_{\text {ex }}=458 \mathrm{~nm}, \lambda_{\text {em }}=545 \mathrm{~nm}$; sulforhodamine: $\lambda_{\text {ex }}=586 \mathrm{~nm}, \lambda_{\text {em }}=602 \mathrm{~nm}$ ). Measurements were performed in duplicate.

The pulmonary deposition of the dry powders was also assessed using an MSLI equipped with a USP induction port (Copley Scientific, Nottingham, UK). The stages of the MSLI were filled with $20 \mathrm{~mL}$ of water. The powder liberated from the Spinhaler inhaler was drawn through the impinger at an airflow of 30,60 , or $100 \mathrm{~L} / \mathrm{min}$, for a period of 8,4 , or $2.4 \mathrm{~s}$, respectively, in order to aspirate $4 \mathrm{~L}$ of air. ${ }^{14}$ The powder deposited on the four levels and in the throat was recovered by removing the initial water and rinsing with additional fractions of water and ethanol up to reaching a total of $250 \mathrm{~mL}$ of a $60 \%$ ethanolic solution. After complete dissolution of the particles, the fluorescence of each solution, due to sulforhodamine incorporated in the dry powder, was determined as above. Measurements were performed in duplicate. 
For both impactors, the emitted dose was determined as the percent of total powder mass exiting the capsule. The cumulative mass of powder less than the stated size of each stage of the impactor was calculated and plotted on a log probability scale, as percent of total mass recovered in the impactor against the effective cut-off diameter. The experimental mass median aerodynamic diameter (MMAD) of the particles was defined from this graph as the particle size at which the line crosses the 50\% mark and the geometric standard deviation (GSD) as GSD $=\sqrt{\frac{\text { size } X}{\operatorname{size} Y}}$, where size $X$ is the particle size for which the line crosses the $84 \%$ mark and size $Y$ the $16 \%$ mark. The fine particle fraction was calculated by interpolation from the same plot as the fraction of powder emitted from the inhaler with an aerodynamic diameter $\leq 5 \mu \mathrm{m} .{ }^{14}$

\section{HPLC}

PTH content in the powders and concentrations in solutions (see below, Binding of PTH to Albumin) were measured by reverse-phase (RP) HPLC with the Hewlett Packard series 1050 system (Agilent Technologies, Palo Alto, CA) using an RP $\mathrm{C}_{18}$ Jupiter column $(250 \times 4.60 \mathrm{~mm}$ i.d., $5 \mu \mathrm{m}$, $300 \AA$ A; Phenomenex, Torrance, CA) maintained at $35^{\circ} \mathrm{C}^{15,16}$ Isocratic separation was achieved using a water/acetonitrile/trifluoroacetic acid (33:67:0.1) solvent system at a flow rate of $1 \mathrm{~mL} / \mathrm{min}$. The column effluent was directed to a variable wavelength detector set to monitor absorbance at $214 \mathrm{~nm}$. Samples were prepared by suspending the powder in the mobile phase, followed by $2 \mathrm{~min}$ of sonication, and centrifugation at $3000 \mathrm{rpm}$, during $10 \mathrm{~min}$ at $4^{\circ} \mathrm{C}$. This sample extraction allowed recovery of $94 \%$ of PTH. The injection volume was $100 \mu \mathrm{L}$. The limit of quantification was $2.5 \mu \mathrm{g} / \mathrm{mL}$, the dosage range was $2.5-$ $50 \mu \mathrm{g} / \mathrm{mL}$, and the intra-assay relative standard deviation (RSD) was $0.4-1.3 \%$ over this range.

\section{Mass Spectrometry}

A combination of HPLC (Hewlett Packard series 1100 system; Agilent Technologies) and mass spectrometry (Sciex API 365, PerkinElmer, Sciex Instruments, Thornhill, Ontario, Canada) was performed using the $\mathrm{RP}_{18}$ Jupiter column with a water/acetonitrile/trifluoroacetic acid (36:64:0.1) mobile phase at a flow rate of $600 \mu \mathrm{L} / \mathrm{min}$ and a pressure of 78 bar. ${ }^{17}$ The column effluent was directed to a variable wavelength detector set to monitor absorbance at $214 \mathrm{~nm}$, and thereafter with a splitter into a Sciex API 365 triple quadrupole mass spectrometer with Turbo Ion Spray maintained at $475^{\circ} \mathrm{C}$. Samples were prepared with the mobile phase, as described above, in order to obtain a PTH concentration of $1 \mu \mathrm{g} / \mathrm{mL}$. The injection volume was $80 \mu \mathrm{L}$. Full scan spectra were obtained by scanning quadrupole- 1 from 500 to $2000 \mathrm{~m} / \mathrm{z}$ with a step size of 2 atomic mass units. Data were processed using the data analysis program MassChrom 1.1.

\section{Pharmacokinetic Studies}

Catheters for blood sampling and intravenous (iv) injection (CBAS-C30 Solo-Cath $3 \mathrm{Fr} \times 80 \mathrm{~cm}$; Instech Solomon, Plymouth Meeting, PA) were implanted in the jugular veins of the animals $24 \mathrm{~h}$ before the pharmacokinetic study. Rats were anesthetized with $700 \mu \mathrm{L}$ of Thalamonal and then received a PTH dose by iv or sc injections, intratracheal insufflation of a dry powder, or intratracheal instillation of a solution. All PTH solutions were made with phosphate buffer, $0.5 \mathrm{mM}$ at $\mathrm{pH} 7.4$, and the volume administered was adjusted to the rat weight to keep the dose per kilogram constant.

The iv solution of PTH was administered at a dose of $44.4 \mu \mathrm{g} / \mathrm{kg}$ in an approximate volume of $0.5 \mathrm{~mL}$. The sc solutions contained PTH and $0.3 \%$ albumin, or were without albumin, and were administered at a dose of 22.2 or $44.4 \mu \mathrm{g} / \mathrm{kg}$, respectively, both in an approximate volume of $0.1 \mathrm{~mL}$.

Two types of powder, powder $\mathrm{A}^{\prime}$ made of PTH/ albumin/lactose/DPPC and B made of PTH/ lactose/DPPC (further described in Table 1), were administered intratracheally with the PennCentury insufflator (model DP-3; Penn-Century, Inc., Philadelphia, PA). The delivery tube of the insufflator containing the powder sample was placed through the mouth into the trachea of the animal. Administration of the powder was made by insufflation of $3 \mathrm{~mL}$ of air contained in a syringe connected to the device. The insufflator was weighed before and after powder filling, and after administration, to know the actual dose insufflated. Approximately $2.07 \pm 0.08 \mathrm{mg}$ of powder $\mathrm{A}^{\prime}$ or $238 \pm 12 \mu \mathrm{g}$ of powder B, and therefore a mean PTH dose of $20.7 \mu \mathrm{g}$ or $20.4 \mu \mathrm{g}$, respectively, were delivered. These doses per rat corresponded to approximately $44.4 \mu \mathrm{g}$ per $\mathrm{kg}$.

In the case of the intratracheal instillation, PTH $(0.1 \mathrm{~mL}, 44.4 \mu \mathrm{g} / \mathrm{kg})$ was directly instilled in the trachea by inserting a curved Hamilton syringe 
Table 1. Composition, Particle Sizes, and Tap Density of the Dry Powders

\begin{tabular}{lcccccccc}
\hline Identification & $\begin{array}{c}\text { PTH } \\
(\%)\end{array}$ & $\begin{array}{c}\text { Albumin } \\
(\%)\end{array}$ & $\begin{array}{c}\text { Lactose } \\
(\%)\end{array}$ & $\begin{array}{c}\text { Trehalose } \\
(\%)\end{array}$ & $\begin{array}{c}\text { DPPC } \\
(\%)\end{array}$ & $\begin{array}{c}\text { Size }^{a} \\
(\mu \mathrm{m})\end{array}$ & $\begin{array}{c}\text { Tap Density }^{b} \\
\left(\mathrm{~g} / \mathrm{cm}^{3}\right)\end{array}$ & $\begin{array}{c}d_{\text {aer }}{ }^{c} \\
(\mu \mathrm{m})\end{array}$ \\
\hline Type A & 0 & 30 & 10 & 0 & 60 & $4.7 \pm 0.1$ & $0.039 \pm 0.006$ & $0.92 \pm 0.05$ \\
Type A $^{\prime}$ & 1 & 30 & 10 & 0 & 60 & 4.74 & 0.056 & 1.12 \\
Type B & 10 & 0 & 30 & 0 & 60 & 4.34 & 0.063 & 1.09 \\
Type C & 2 & 0 & 38 & 0 & 60 & 4.14 & 0.071 \\
Type D & 2 & 0 & 0 & 38 & 60 & 4.70 & 0.111 & 1.10 \\
\hline
\end{tabular}

Geometric particle sizes,${ }^{a}$ tap densities,${ }^{b}$ and computed primary aerodynamic diameters ${ }^{c}$ are presented as mean \pm SEM from five powders (type A) or are values from individual powders (types $\mathrm{A}^{\prime}-\mathrm{D}$ ). Aerosolization properties were assessed on powders $\mathrm{A}, \mathrm{A}^{\prime}$ and $\mathrm{B}$ and chemical integrity of PTH on powders $\mathrm{C}$ and D.

through the mouth (Alltech, Lokeren, Belgium). Immediately after instillation, a 3 -mL air bolus was insufflated in the lung using the insufflator.

The changes in plasma PTH levels after administration were determined in 4-8 rats/group. Blood samples $(0.3 \mathrm{~mL})$ were collected from the jugular vein into lithium-heparinized tubes (Microtainer brand tubes lithium heparin; Becton Dickinson, Aalst, Belgium) before and at (2.5), 5, $10,15,25,40,60,(90), 120$, and 180 min after administration, and were replaced by the administration of $0.3 \mathrm{~mL}$ of saline to compensate the decrease in blood volume. The plasma was separated by centrifugation $\left(15 \mathrm{~min}\right.$ at $3300 \mathrm{~g}$ and $4^{\circ} \mathrm{C}$ ) within $30 \mathrm{~min}$ of collection and stored at $-20^{\circ} \mathrm{C}$ until analysis by a 1-34 PTH radioimmunoassay (Bachem, former Peninsula Laboratories, Merseyside, UK). The radioimmunoassay uses a rabbit antiserum raised against human parathyroid hormone (1-34) and specific for the $\mathrm{COOH}-$ terminal part of the PTH molecule. Cross-reactivity is $100 \%$ for rat-PTH (1-34) and $18 \%$ for hPTH(1-84). The antibody cannot distinguish the 1-34 from the 3-34 fragment; therefore, PTH measured by the immunoassay was immunoreactive PTH and not necessarily the bioactive fragment. The intra-assay RSD was 9\% and the limit of detection was $10 \mathrm{pg} / \mathrm{mL}$. Plasma samples were assayed at proper dilutions, in duplicate, within 1 month of storage (no loss of immunoreactivity was noted over this period) and PTH concentrations were calculated by curve-fitting using the PTH plasma standards. The areas under the plasma concentration-time curve (AUC) were calculated using the linear trapezoidal rule. The maximal plasma concentration $\left(\mathrm{C}_{\max }\right)$ and the time to peak $\left(t_{\text {max }}\right)$ were obtained from the individual concentration-time curves. The bioavailability parameters (absolute and relative bioavailability, $F_{\text {abs }}$ and $\mathrm{F}_{\text {rel }}$ ) were calculated as (AUC-dose ref $/$ $\mathrm{AUC}_{\text {ref }} \cdot$ dose) $\cdot 100$ and the plasma elimination half-life $\left(t_{1 / 2}\right)$ as $\ln 2 / k$. The elimination rate constant $(k)$ was estimated by linear regression of the last time points of the log concentration versus time curve. The clearance (CL) was calculated as [dose $\cdot \mathrm{F}_{\mathrm{abs}}$ ]/AUC and the volume of distribution (Vd) as CL/ $k .^{18}$

\section{Binding of PTH to Albumin}

The binding of PTH to albumin was determined by equilibrium dialysis, using Teflon dialysis cells (Dianorm System, Münich, Germany), under a constant stirring at $20 \mathrm{rpm}$. The dialysis was performed using cellulose membranes (Spectra/ Por2 Membrane Discs; Spectrum Medical Industries, Los Angeles, CA) with a molecular weight cut-off of $12-14 \mathrm{kDa}$, during $6 \mathrm{~h}$, at $25^{\circ} \mathrm{C}$ or $37^{\circ} \mathrm{C}$ for experiment $\mathrm{A}$ and $\mathrm{B}$, respectively. The time necessary to reach equilibrium ( $6 \mathrm{~h}$ ) was evaluated beforehand by measuring binding of PTH to rat plasma after 2- to 8-h dialysis.

In experiment $\mathrm{A}, 1 \mathrm{~mL}$ of isotonic phosphate buffer $\left(0.78 \mathrm{~g} / \mathrm{L} \mathrm{NaH} \mathrm{NO}_{4} \cdot 1 \mathrm{H}_{2} \mathrm{O}, 4 \mathrm{~g} / \mathrm{L}\right.$ $\mathrm{Na}_{2} \mathrm{HPO}_{4} \cdot 2 \mathrm{H}_{2} \mathrm{O}, 5.58 \mathrm{~g} / \mathrm{L} \mathrm{NaCl} ; \mathrm{pH}$ 7.4) containing $200 \mu \mathrm{g}$ of PTH and $3 \mathrm{mg}$ of human serum albumin was dialyzed against $1 \mathrm{~mL}$ of isotonic phosphate buffer. Intact PTH was assayed by HPLC in both compartments, as described above. The recovery of intact $\mathrm{PTH}$ from the Teflon dialysis cells was $82 \pm 3 \%$.

In experiment $\mathrm{B}, 1 \mathrm{~mL}$ of rat plasma containing $200 \mu \mathrm{g}$ of PTH or spiked with $6,30,60,150$, or $300 \mathrm{ng}$ of PTH and $\left(\left[{ }^{125} \mathrm{I}\right]-\mathrm{Tyr}^{0}\right)-\mathrm{hPTH}(1-34)$ as a tracer (1\% relative to PTH concentration) was dialyzed against $1 \mathrm{~mL}$ of isotonic phosphate buffer. At microgram concentrations, intact PTH was measured in both compartments by HPLC. At nanogram concentrations, the radioactivity of both compartments was determined in a gammacounter (Auto Gamma Scintillation Spectrometer Packard type 5230; Canberra Packard Benelux, 
Zelik, Belgium). No protease inhibitors were added to plasma because they might interfere in binding. Although HPLC data indicate the appearance of PTH byproducts over time, the total recovery of intact PTH from the Teflon dialysis cells decreased by only $20 \%$ from 0 to $6 \mathrm{~h}$ dialysis, suggesting that enzymatic byproducts involved $20 \%$ of PTH at most. This is supported by Seibel et al. ${ }^{19}$ who measured 16\% decrease in PTH concentration in dog plasma in the nanogram range after $4 \mathrm{~h}$ at room temperature.

Concentration of albumin before and after dialysis was determined by the bromocresol green method (Sigma Diagnostics, St. Louis, MO) in order to assess the volume shift. ${ }^{20}$ The fraction unbound (fu) was calculated as the concentration of unbound PTH in the buffer compartment $(\mathrm{Cu})$ divided by the total concentration of PTH in the albumin compartment $(\mathrm{Cp})$. The fraction unbound corrected for the volume shift $\left(\mathrm{fu}^{\prime}\right)$ is calculated as $\mathrm{fu}^{\prime}=1 /\left[1+\left(\mathrm{Pt}^{\prime}(1+\mathrm{fu}) /(\mathrm{fu} \cdot \mathrm{Pt})\right)\right]$, where $\mathrm{Pt}$ and $\mathrm{Pt}^{\prime}$ are the albumin concentrations before and after dialysis, respectively. The binding \% of PTH to albumin is equal to $\left(1-\mathrm{fu}^{\prime}\right) \cdot 100 .^{20}$ Measurements were performed in duplicate.

\section{Pulmonary Safety Studies}

A pulmonary safety study was performed after a single acute exposure to two types of powders. The animals (5-7 rats/group) were anesthetized with $700 \mu \mathrm{L}$ of ketamine/xylazine $(50 / 5.56 \mathrm{mg} / \mathrm{mL})$ and approximately $2 \mathrm{mg}$ of powder A or B (Table 1) were then delivered intratracheally using the insufflator. The control group received an air bolus of $3 \mathrm{~mL}$, without powder delivery. An additional group remained untreated. The animals were sacrificed with an overdose of pentobarbital 4, 24, or $48 \mathrm{~h}$ after treatment. Bronchoalveolar lavages (BAL) were obtained by slowly injecting $10 \mathrm{~mL}$ of HBSS (without $\mathrm{Ca}^{++}, \mathrm{Mg}^{++}$and phenol-red, in order to minimize cell clumping) into the trachea, waiting for $30 \mathrm{~s}$, and then withdrawing the liquid from the lung. The lavage procedure was repeated with four additional $10-\mathrm{mL}$ aliquots until a total volume of $50 \mathrm{~mL}$ was injected. The BAL was centrifuged at $700 \mathrm{~g}$ during $10 \mathrm{~min}$ at $4^{\circ} \mathrm{C}$.

The tolerability of the lung to the powders was assessed by analyzing biochemical and cellular components in BAL. Lactate dehydrogenase (LDH) activity and total protein content were measured in the cell-free supernatant of the first lavage fraction. LDH activity was assayed spectrophotometrically by monitoring the reduction of $\mathrm{NAD}^{+}$at
$340 \mathrm{~nm}$ in the presence of lactate (Technicon RA System; Bayer Diagnostics, Domont, France). Total protein concentration was measured by the Pyrogallol red method using the Bio-Rad kit and human serum albumin as standard (Technicon RA System). The cell pellets pooled from the five aliquots were resuspended in $5 \mathrm{~mL}$ of HBSS and the total number of cells was determined by Türck staining and counting with a hemocytometer. The cell differential counting (300 cells per rat) was performed on cytocentrifuge preparations fixed in methanol and stained with Diff Quick (Dade Berhing AG, Düdingen, Switzerland). ${ }^{21}$

The safety of inhaling the dry powders was also assessed by lung histology. Approximately 2 or $10 \mathrm{mg}$ of powder A (Table 1) were insufflated with the PennCentury device or after tracheotomy using a Harvard ventilator (Harvard Apparatus, Ltd., Edendridge, UK), respectively, to three rats/ group. The control group received an air bolus of $2 \mathrm{~mL}$. The animals were sacrificed 4 or $48 \mathrm{~h}$ after treatment using pentobarbital and the different lobes and the trachea were removed and placed in a $4 \%$ formol solution. Paraffin-embedded histological sections were stained with hematoxylin and eosin and examined by light microscopy.

\section{Statistics}

The data were validated by the Dixon test. All results are expressed as mean \pm standard error of the mean (SEM). One-way analysis of variance (ANOVA) test and the Tukey test were performed to demonstrate statistical differences $(p<0.05)$, using the software Sigma-Stat for Windows (SPSS Inc., San Rafael, CA).

\section{RESULTS}

\section{Powder Preparation and Characterization}

Dry powders were formed of the 1-34 fragment of human parathyroid hormone and the following excipients in varying proportions: albumin, lactose, trehalose, and/or DPPC. The powders were prepared by spray-drying using the formulation and spray-drying parameters previously optimized in terms of powder aerodynamic behavior in cascade impactors in vitro. ${ }^{10}$ The excipients and proportions used as well as the primary geometric particle size, bulk powder density, and theoretical estimate of the primary aerodynamic diameter of the main powder aerosols described in this article are detailed in Table 1. 
Good reproducibility of the dry powder preparation was demonstrated by producing and characterizing five powders made of albumin/lactose/ DPPC (powder A in Table 1). The dry powders presented a geometric particle size of $4.7 \pm 0.1 \mu \mathrm{m}$ (RSD 5\%), a tap density of $0.039 \pm 0.006 \mathrm{~g} / \mathrm{cm}^{3}$ (RSD 3\%), and a computed primary particle aerodynamic diameter $\left(d_{\text {aer }}\right)$ of $0.92 \pm 0.05 \mu \mathrm{m}$ (RSD $5 \%)$. The emitted dose in the Andersen cascade impactor operated at $28.3 \mathrm{~L} / \mathrm{min}$ using a Spinhaler inhaler device reached $77.4 \pm 0.6 \%$ (RSD 7\%), the fine particle fraction $41 \pm 1 \%$ (RSD 13\%), the experimental MMAD $5.7 \pm 0.2 \mu \mathrm{m}$ (RSD 8\%), and the geometric standard deviation $1.74 \pm 0.06$ (RSD 5\%). The dry powders exhibited an MMAD approximately six-fold higher than their $d_{\text {aer }}$, suggesting that the powders exited the inhaler as aggregates. Aggregation is supported by ongoing direct measurement of the geometric diameter of particles and particle aggregates at the inhaler exit in the case of similar powders (data not shown).

The impact of varying the airflow rate from 30 to $100 \mathrm{~L} / \mathrm{min}$ on the in vitro pulmonary deposition of powder $\mathrm{A}^{\prime}$, made of PTH/albumin/lactose/ DPPC, and powder B, made of PTH/lactose/DPPC (Table 1), was assessed in the MSLI. There was no influence of the airflow rate on the emitted dose for both dry powders (Fig. 1a; Tukey test, $p>0.05$ ). Overall, the airflow did not affect the fine particle fraction and the MMAD of powder A' (Fig. 1; Tukey test, $p>0.05$ ). However, increasing the airflow significantly increased the fine particle fraction and decreased the MMAD for powder B (Fig. 1; Tukey test, $p<0.05$ ).

The aerodynamic behavior of powders $\mathrm{A}^{\prime}$ and $\mathrm{B}$ in the MSLI operated at $30 \mathrm{~L} / \mathrm{min}$ was similar to that in the Andersen cascade impactor operated at $28.3 \mathrm{~L} / \mathrm{min}$. The fine particle fraction of powder $\mathrm{A}^{\prime}$ was $52.9 \%$ in the MSLI and $46.4 \%$ in the Andersen impactor (Tukey test, $p<0.05$ ); the values for powder B were 40.2 and $37.8 \%$, respectively (Tukey test, $p>0.05$ ). Similar aerodynamic behavior in both apparatuses indicates that the wet atmosphere in the MSLI did not markedly affect the pulmonary deposition of the dry powders despite powder hygroscopy resulting from DPPC and the protein.

PTH content and integrity in the dry powders were assessed by HPLC and mass spectrometry. The actual PTH titer of the powders ranged between 85.5 and $100.6 \%$ relative to the theoretical titer of $100 \%$ and was taken into account for calculating the doses of PTH delivered to rats in the pharmacokinetic studies (see below). Powder C
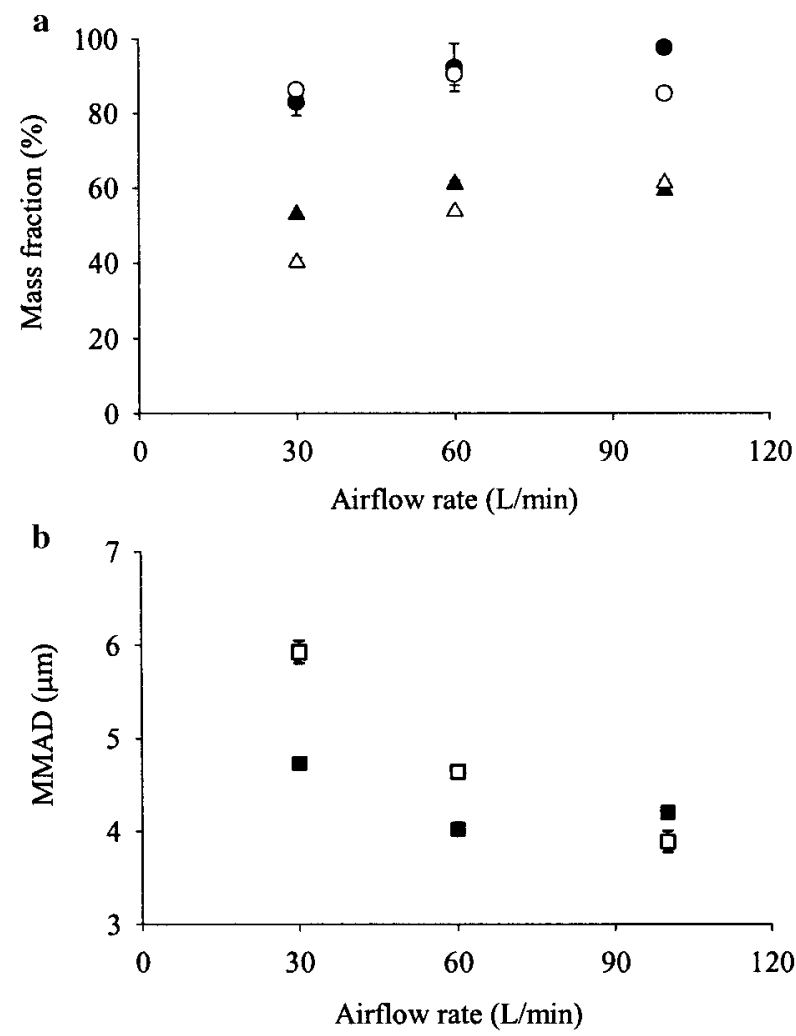

Figure 1. Influence of the airflow on the aerosolization properties of powders $\mathrm{A}^{\prime}$ and $\mathrm{B}$ assessed in the Multi-Stage Liquid Impinger. (a) Emitted doses (, $\mathrm{A}^{\prime}$; $\bigcirc, \mathrm{B})$ and fine particle fractions $\left(\boldsymbol{\Lambda}, \mathrm{A}^{\prime} ; \triangle, \mathrm{B}\right)$; (b) MMAD $\left(\square, \mathrm{A}^{\prime} ; \square, \mathrm{B}\right)$. Error bars are standard errors of the means.

formed of PTH/lactose/DPPC and D formed of $\mathrm{PTH} /$ trehalose/DPPC (Table 1) were tested for physicochemical integrity of PTH after formulation. Lactose is a reducing sugar that has the potential to react with the primary amine of lysine residues and generate Schiff-based byproducts. ${ }^{22}$ However, the mass spectrum of powder $\mathrm{C}$ containing lactose did not show any byproducts resulting from a covalent bond between the sugar and PTH, as did not the spectrum of powder D containing trehalose, a nonreducing sugar (data not shown). No peaks from other degradation products were observed by either HPLC or mass spectrometry.

An electron microscope image of a powder formed of albumin, trehalose, and DPPC is shown in Figure 2 as an example. The particles presented a mixture of spherical and toroidal morphologies.

\section{Pharmacokinetic and Binding Studies}

To assess the efficacy of the dry powders for systemic PTH delivery, immunoreactive PTH plasma 


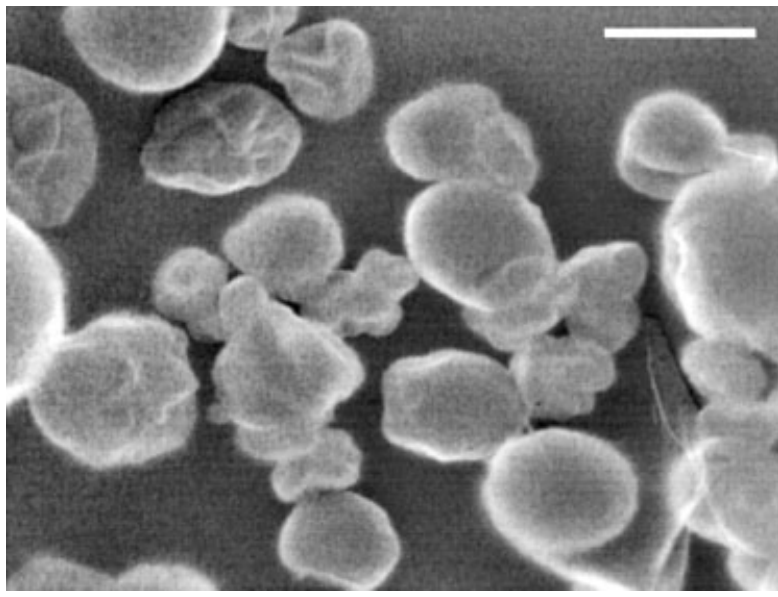

Figure 2. Scanning electron microscope image of particles made of albumin, trehalose, and DPPC $(25: 25: 50, \mathrm{w} / \mathrm{w} / \mathrm{w})$. Scale bar is $5 \mu \mathrm{m}$.

levels were measured after inhalation of the dry powder, iv and sc injections in rats (Fig. 3). In contrast to the iv solution, the sc solution of PTH contained $0.3 \%$ of albumin. Albumin was originally added to the sc solution to protect the peptide against anionic and hydrophobic adsorption on container surfaces. As shown in Table 2, the absolute bioavailabilities of immunoreactive PTH $\left(\mathrm{F}_{\text {abs }}\right)$ were $9 \%$ and $21 \%$ for sc and powder $\mathrm{A}^{\prime}$, respectively.

Because $\mathrm{F}_{\mathrm{abs}}$ was particularly low after sc, a binding of PTH to albumin was suspected. The binding of PTH to albumin (and possibly to other plasma proteins) was assessed by equilibrium dialysis (Table 3 ). In experiment $A$ where the

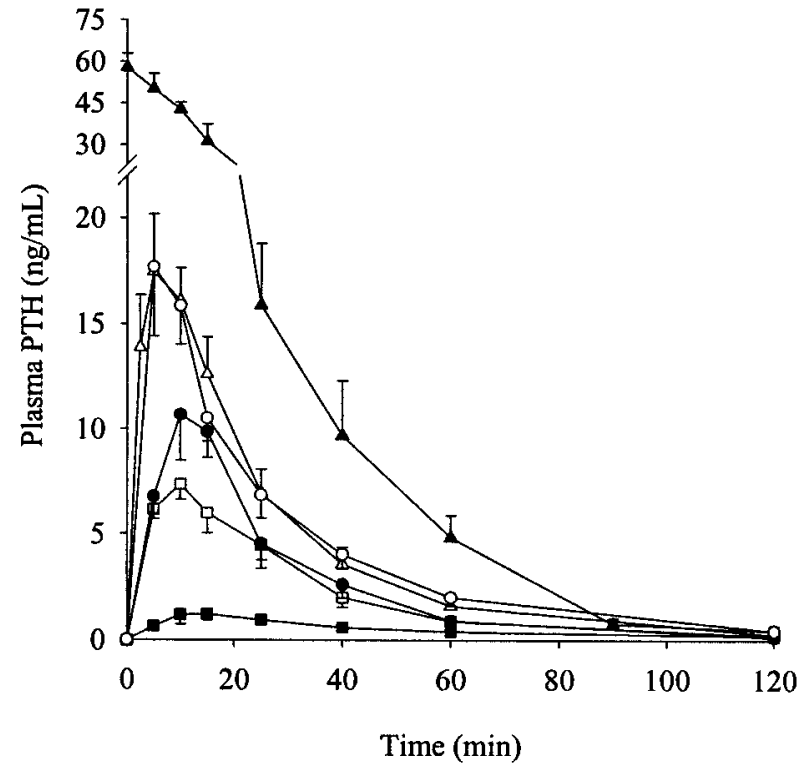

Figure 3. Immunoreactive PTH plasma concentration-time curves after $(\boldsymbol{\Lambda})$ iv injection of $19 \mu \mathrm{g}$ of PTH $(n=4),(\triangle)$ intratracheal instillation of $19 \mu \mathrm{g}$ of $\mathrm{PTH}$ $(n=7),(\square)$ sc injection of $10 \mu \mathrm{g}$ of PTH with $0.3 \%$ albumin $(n=5),(\square)$ sc injection of $19 \mu \mathrm{g}$ of $\mathrm{PTH}$ (no albumin, $n=5)$ and following ( ) powder $\mathrm{A}^{\prime}(21 \mu \mathrm{g}$ of PTH, with albumin; $n=6)$, and $(\bigcirc)$ powder B (20 $\mu \mathrm{g}$ of PTH, no albumin; $n=8$ ) inhalation. Error bars are standard errors of the means.

concentrations of the sc solution were tested $(200 \mu \mathrm{g} / \mathrm{mL}$ PTH and $3 \mathrm{mg} / \mathrm{mL}$ albumin in phosphate buffer), a $78 \%$ binding was observed. In experiment $\mathrm{B}$, at $\mathrm{PTH}$ concentrations varying from 6 to $300 \mathrm{ng} / \mathrm{mL}$ in rat plasma, a constant and average binding of $71 \%$ was measured. The

Table 2. Pharmacokinetic Parameters

\begin{tabular}{|c|c|c|c|c|c|c|}
\hline & $\operatorname{iv}^{a}$ & $\begin{array}{l}\mathrm{sc}^{b} \text { (with } \\
\text { Albumin) }\end{array}$ & sc (No Albumin) & $\mathrm{it}^{c}$ & $\begin{array}{c}\text { Inhalation of } \\
\text { Powder } \mathrm{A}^{\prime}\end{array}$ & $\begin{array}{c}\text { Inhalation of } \\
\text { Powder B }\end{array}$ \\
\hline No. of rats & 4 & 5 & 5 & 5 & 6 & 8 \\
\hline Rat weight (g) & $428 \pm 10$ & $429 \pm 12$ & $436 \pm 5$ & $418 \pm 5$ & $447 \pm 7$ & $416 \pm 12$ \\
\hline PTH dose/rat $(\mu \mathrm{g})^{d}$ & $19.0 \pm 0.4$ & $9.5 \pm 0.3$ & $19.4 \pm 0.2$ & $18.6 \pm 0.2$ & $20.7 \pm 0.8$ & $20 \pm 1$ \\
\hline $\mathrm{C}_{0}$ or $\mathrm{C}_{\max }(\mathrm{ng} / \mathrm{mL})^{e}$ & $58 \pm 5$ & $1.5 \pm 0.4$ & $7.9 \pm 0.7$ & $20 \pm 2$ & $12 \pm 2$ & $20 \pm 3$ \\
\hline $\mathrm{t}_{\max }(\min )^{f}$ & & $15 \pm 3$ & $10 \pm 2$ & $6 \pm 1$ & $11 \pm 1$ & $7 \pm 1$ \\
\hline $\mathrm{AUC}(\mathrm{ng} \cdot \mathrm{min} / \mathrm{mL})^{g}$ & $1367 \pm 39$ & $65 \pm 9$ & $249 \pm 40$ & $507 \pm 70$ & $295 \pm 36$ & $511 \pm 64$ \\
\hline $\mathrm{CL}(\mathrm{mL} / \mathrm{min})^{h}$ & $14.7 \pm 0.4$ & $17 \pm 2$ & $16 \pm 2$ & $17 \pm 3$ & $16 \pm 3$ & $17 \pm 2$ \\
\hline $\mathrm{Vd}(\mathrm{mL})^{i}$ & $301 \pm 20$ & $530 \pm 69$ & $458 \pm 108$ & $415 \pm 56$ & $414 \pm 58$ & $553 \pm 76$ \\
\hline $\mathrm{t}_{1 / 2}(\min )^{j}$ & $14 \pm 1$ & $22 \pm 1$ & $20 \pm 3$ & $18 \pm 2$ & $19 \pm 1$ & $24 \pm 2$ \\
\hline $\mathrm{F}_{\mathrm{abs}}(\%)^{k}$ & & $9 \pm 2$ & $18 \pm 3$ & $37 \pm 6$ & $21 \pm 3$ & $34 \pm 5$ \\
\hline $\mathrm{F}_{\text {rel }}$ to $\mathrm{sc}(\%)^{l}$ & & & & $204 \pm 61$ & $113 \pm 32$ & $186 \pm 53$ \\
\hline
\end{tabular}

${ }^{a}$ intravenous injection; ${ }^{b}$ subcutaneous injection; ${ }^{c}$ intratracheal instillation; ${ }^{d}$ all rats received approximately $44.4 \mu \mathrm{g}$ PTH $/ \mathrm{kg}$ except for the sc (with albumin) study in which the dose was $22.2 \mu \mathrm{g} \mathrm{PTH} / \mathrm{kg} ;{ }^{e}$ maximal plasma concentration of immunoreactive PTH; ${ }$ time to peak; ${ }^{g}$ area under the plasma concentration-time curve; ${ }^{h}$ clearance; ${ }^{i}$ volume of distribution; ${ }^{j}$ elimination half-life; ${ }^{k}$ absolute bioavailability and ${ }^{l}$ bioavailability relative to the sc without albumin. Data are presented as mean $\pm \mathrm{SEM}$. 
Table 3. Binding of PTH to Albumin

\begin{tabular}{|c|c|c|}
\hline PTH Concentration & $\begin{array}{c}\text { Albumin } \\
\text { Concentration }^{a} \\
(\mathrm{mg} / \mathrm{mL})\end{array}$ & Binding $(\%)$ \\
\hline \multicolumn{3}{|l|}{ Experiment $A^{b}$} \\
\hline $200 \mu \mathrm{g} / \mathrm{mL}$ & 3 & 78 \\
\hline \multicolumn{3}{|l|}{ Experiment $\mathrm{B}^{c}$} \\
\hline $6 \mathrm{ng} / \mathrm{mL}$ & 32 & 71 \\
\hline $30 \mathrm{ng} / \mathrm{mL}$ & 32 & 71 \\
\hline $60 \mathrm{ng} / \mathrm{mL}$ & 32 & 72 \\
\hline $150 \mathrm{ng} / \mathrm{mL}$ & 32 & 71 \\
\hline $300 \mathrm{ng} / \mathrm{mL}$ & 32 & 71 \\
\hline $200 \mu \mathrm{g} / \mathrm{mL}$ & 26 & 67 \\
\hline
\end{tabular}

${ }^{a}$ Albumin concentration in phosphate buffer (experiment A) or in rat plasma (experiment B) was measured before dialysis by the bromocresol green method, ${ }^{b} \mathrm{PTH}$ and human serum albumin were dialyzed in duplicate against isotonic phosphate buffer at $25^{\circ} \mathrm{C}$ for $6 \mathrm{~h}$, and ${ }^{c}$ rat plasma samples spiked with different PTH concentrations were dialyzed in duplicate against isotonic phosphate buffer at $37^{\circ} \mathrm{C}$ for $6 \mathrm{~h}$.

constancy in binding shows that PTH plasma concentrations were low relative to the concentration of total protein binding sites. At $200 \mu \mathrm{g} / \mathrm{mL}$ PTH in rat plasma, the binding was still $67 \%$ (Table 3).

To assess the influence of albumin incorporated in the formulations on the systemic bioavailability of immunoreactive PTH, a pharmacokinetic study was performed after sc administration of an albumin-free PTH solution as well as after insufflation of powder B prepared without albumin (Table 1). The $\mathrm{F}_{\mathrm{abs}}$ of PTH by sc injection increased from 9 to $18 \%$ in absence of albumin (Fig. 3, Table 2). Because the areas under plasma concentration-time curves have been shown proportional to the sc dose, ${ }^{23}$ we assumed that the increase in
$\mathrm{F}_{\mathrm{abs}}$ originated from albumin withdrawal rather than from the increase in sc dose (Table 2). Similarly, the removal of albumin from the powder formulation increased the $\mathrm{F}_{\mathrm{abs}}$ of PTH from 21 to $34 \%$ at the same PTH doses. The $\mathrm{F}_{\mathrm{abs}}$ after intratracheal insufflation of powder B was almost twice as high as that after the albumin free sc (Fig. 3, Table 2).

Identical pharmacokinetic profile and parameters were obtained after inhalation of powder $\mathrm{B}$ and intratracheal instillation (Fig. 3; ANOVA, $p>0.05$ ). In contrast, the absorption rate was higher after inhalation of powder B than after sc injection (Fig. 3, Table 2).

There was no statistical difference between the clearance (CL), the volume of distribution $(\mathrm{Vd})$, and the elimination half-life $\left(t_{1 / 2}\right)$ of each route of administration (ANOVA and Tukey, $p>0.05$ ), except for $t_{1 / 2}$ of the iv route relative to inhalation of powder B (Tukey, $p<0.05$ ).

\section{Pulmonary Safety Studies}

The safety of dry powder inhalation after a single acute exposure was demonstrated by measuring biochemical and cellular markers of inflammation in BAL and by lung histology. Table 4 shows the biochemical and cellular components of BAL of an untreated group as well as at 4, 24, and $48 \mathrm{~h}$ after delivery of dry powders A or B, or of an air bolus (control group). Overall, neither increase in the total number of cells (Tukey test, $p>0.05$, except $24 \mathrm{~h}$ after powder B delivery), neutrophils (Tukey test, $p>0.05$ ), or lactate dehydrogenase (Tukey test, $p>0.05$ ), nor appearance of eosinophils was noted in both powder groups, as compared with

Table 4. Biochemical and Cellular Components in Bronchoalveolar Lavages

\begin{tabular}{|c|c|c|c|c|c|}
\hline Group & $\operatorname{Time}^{a}(\mathrm{~h})$ & $\mathrm{LDH}^{b}$ Activity (U/L) & Total Proteins (mg/L) & $\begin{array}{l}\text { Total Cells/ } \\
\text { Lung }\left(.10^{6}\right)\end{array}$ & Neutrophils (\%) \\
\hline Untreated & & $40 \pm 2$ & $43 \pm 4$ & $1.8 \pm 0.3$ & $1.0 \pm 0.3$ \\
\hline \multirow[t]{3}{*}{ Control $^{c}$} & 4 & $41 \pm 2$ & $74 \pm 24$ & $1.0 \pm 0.1$ & $5 \pm 1$ \\
\hline & 24 & $35 \pm 5$ & $161 \pm 77$ & $0.83 \pm 0.06$ & $3.6 \pm 0.7$ \\
\hline & 48 & $42 \pm 4$ & $49 \pm 9$ & $1.2 \pm 0.3$ & $4 \pm 2$ \\
\hline \multirow[t]{3}{*}{ Powder $\mathrm{A}^{d}$} & 4 & $50 \pm 3$ & $204 \pm 11$ & $1.3 \pm 0.2$ & $7 \pm 2$ \\
\hline & 24 & $38 \pm 3$ & $104 \pm 21$ & $0.9 \pm 0.2$ & $7 \pm 1$ \\
\hline & 48 & $50 \pm 4$ & $74 \pm 14$ & $1.4 \pm 0.4$ & $7 \pm 2$ \\
\hline \multirow[t]{3}{*}{ Powder $\mathrm{B}^{d}$} & 4 & $48 \pm 3$ & $270 \pm 86$ & $1.4 \pm 0.3$ & $13 \pm 3$ \\
\hline & 24 & $31 \pm 6$ & $61 \pm 32$ & $1.8 \pm 0.1^{*}$ & $4 \pm 1$ \\
\hline & 48 & $44 \pm 8$ & $27 \pm 3$ & $2.1 \pm 0.4$ & $4.1 \pm 0.8$ \\
\hline
\end{tabular}

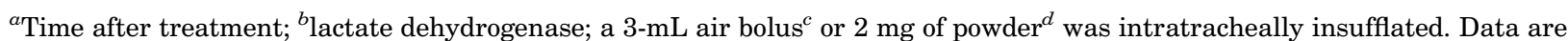
presented as mean \pm SEM $(n=4-5)$. A star symbol indicates significant difference with the control group (Tukey; $p<0.05)$.
} 
the control. The tendency toward increased protein content in the lavages of the treated groups, as compared with the untreated, could be explained by the delivery of dry powders formed of peptides/proteins as well as by the partly invasive mode of pulmonary administration that might cause a slight wound of the trachea wall.

The histology examination of the lung sections $4 \mathrm{~h}$ and $48 \mathrm{~h}$ after powder administration did not reveal any marked differences with the sections of the control group. Neither edematous reaction nor infiltration of macrophages or neutrophils in the alveoli was observed (Fig. 4).

\section{DISCUSSION}

The purpose of this work was to optimize the systemic delivery of the 1-34 fragment of human parathyroid hormone using inhalation dry powders, with the ultimate goal of potentially replacing the sc injection currently tested in clinical studies. ${ }^{2}$ We prepared dry powders of PTH and showed that they presented high emitted doses and fine particle fractions in vitro with limited dependence on airflow rate, and that the peptide incorporated was intact following formulation (Fig. 1). We showed that inhalation of the PTH powders resulted in high absolute bioavailabilities in rats, without acute inflammatory response (Figs. 3 and 4; Tables 2 and 4). Most originally, we demonstrated that albumin, an excipient used in the formulations, could markedly decrease systemic absorption of the hormone through binding and that an appropriate choice of formulation composition could overcome this issue (Fig. 3, Tables 2 and 3).
Inhalation of powder $\mathrm{B}$, made of $\mathrm{PTH} /$ lactose/ $\operatorname{DPPC}(10: 30: 60 \mathrm{w} / \mathrm{w} / \mathrm{w})$, in rats yielded an absolute bioavailability of $34 \%$ and a bioavailability relative to sc injection of $186 \%$ (Table 2). These high bioavailability values suggest that inhalation dry powders might offer an efficient noninvasive alternative to injection. Patton et al. ${ }^{4}$ previously tested the pulmonary absorption of the 1-34 fragment of parathyroid hormone using intratracheal instillation in rats and obtained a similar absolute bioavailability of $40 \%$. Wolff et al. ${ }^{5}$ compared serum PTH concentrations after iv and sc injections and inhalation exposure using ultrasonic nebulization in rhesus monkeys. The absolute bioavailabilities for sc and inhalation administration were $71 \%$ and $29 \%$, respectively, yielding a bioavailability of pulmonary delivery relative to sc of approximately $40 \%$. The $18 \%$ bioavailability of the albumin free sc injection obtained in our study was low compared with the values obtained for sc injection of PTH in monkeys or other peptides in the clinic in general. ${ }^{24}$ Differences in metabolism, tissue binding, and/or doses between humans, monkeys, and rats might explain these results. ${ }^{25}$ Sinko et al. ${ }^{26}$ similarly obtained an average absolute bioavailability of $16 \%$ for sc injection of salmon calcitonin in rats, whereas values of $70 \%$ are reached in humans. ${ }^{24}$

The pharmacokinetic profile of PTH after inhalation in rats showed a rapid increase and decrease in plasma concentrations, which is beneficial to formation of new bone (Fig. 3). The bone-formative action of PTH relative to its bone-resorptive action has in fact been related to pharmacokinetics with continuous infusion resulting in net loss of bone mass whereas a pulsatile profile of intermittent injections resulted in a net gain. ${ }^{27}$
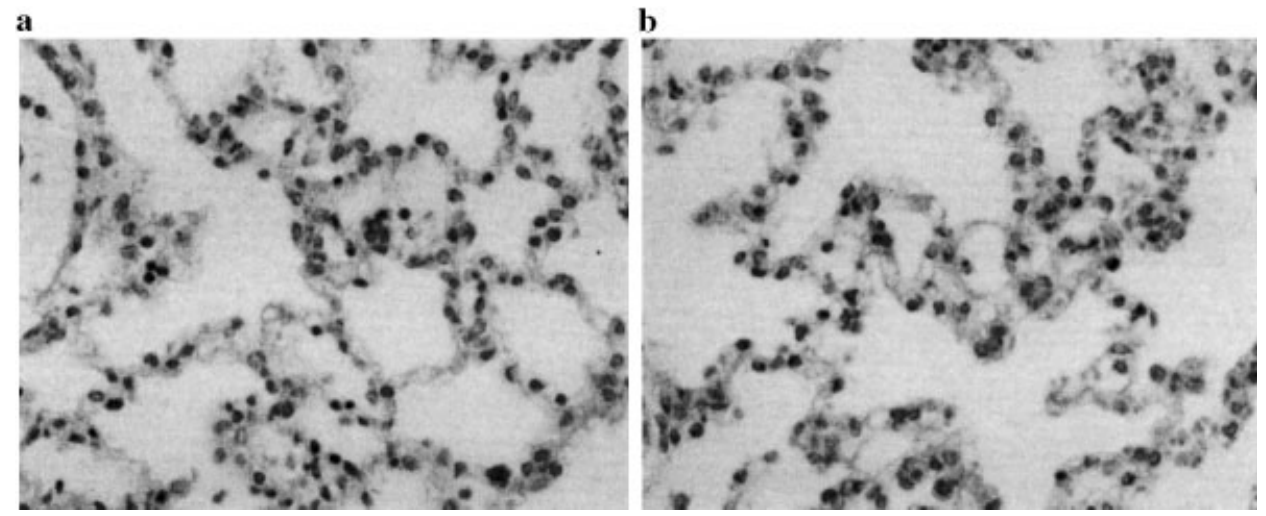

Figure 4. Photomicrographs of eosin-hematoxylin stained lung sections $48 \mathrm{~h}$ after the intratracheal insufflation of an air bolus (a) or $10 \mathrm{mg}$ of powder A (b). 
The incorporation of albumin in the sc solution or in the inhalation dry powders decreased systemic PTH bioavailability 2.0- and 1.6-fold, respectively, as a consequence of PTH binding to albumin (Fig. 3, Tables 2 and 3). Our hypothesis is that binding to albumin increased the duration of PTH presence in the alveolar or sc space and thereby the exposure time of the peptide to local enzymes and/or other degradation processes. Serum albumin is able to carry a wide variety of endogenous and exogenous compounds throughout the body, most significantly, ligands with low molecular mass, high lipophilicity, and negative charges. ${ }^{28,29}$ Peptide and protein hormones have been shown to bind to plasma proteins; for instance, growth hormone circulates bound to the soluble extracellular domain of its membrane receptor. ${ }^{30}$ However, the binding of peptides to albumin has rarely been reported. ${ }^{31} \mathrm{PTH}$ solutions containing albumin or plasma have previously been used for sc injections in preclinical or clinical studies without consideration of binding and the ensuing decrease in systemic bioavailability. ${ }^{23,32}$ Albumin has been used to formulate inhalation dry powders as well. ${ }^{9,10,33}$ Our results indicate that drug binding to excipients is likely to influence drug transport to the systemic circulation in general and that additives might need to be screened for possible binding before in vivo use. The presence of endogenous albumin or other compounds in the alveolar region may decrease systemic absorption of PTH or other drugs aerosolized through similar mechanisms.

PTH bound more to human serum albumin than to rat plasma proteins and at a ratio of PTH to albumin concentrations 1-6 orders of magnitude larger (Table 3). This suggests that the binding affinity to human albumin was higher than to rat albumin, that other proteins from rat plasma did not have a significant role in binding, and/or that endogenous compounds in rat plasma competed for identical binding sites as those of PTH.

The pharmacokinetic profile that follows the pulmonary administration of PTH powder B, prepared without albumin, was superimposed on that following intratracheal instillation of the PTH solution (Fig. 3). This suggests that the initial physical state of PTH had no influence on its systemic absorption and that the other excipients, lactose and DPPC, did not alter absorption as did albumin, provided that the powder and liquid formulations led to a similar deposition within the respiratory tree.
The dry powders prepared in this study differ from conventional powder aerosols by extremely low powder densities $\left(0.04-0.07 \mathrm{~g} / \mathrm{cm}^{3}\right.$ vs. $1.0 \mathrm{~g} / \mathrm{cm}^{3}$ for standard powders) and presented excellent aerosolization properties in impactors in vitro using a Spinhaler device, a first generation suboptimal dry powder inhaler (Fig. 1). The emitted doses reached up to $98 \%$, the fine particle fractions up to $61 \%$, and limited variability in these values was generated by varying the airflow rate from 30 to $100 \mathrm{~L} / \mathrm{min}$. The MMAD of the dry powders of PTH were $4-5(30 \mathrm{~L} / \mathrm{min})$ to $4(100 \mathrm{~L} / \mathrm{min})$ times larger than theoretical estimates of primary aerodynamic diameters (Fig. 1, Table 1), indicating that the powder aerosols exited the inhaler device as particle aggregates and that increasing the airflow rate created insufficient differences in shearing to profoundly impact on the degree of dispersion of these aggregates. This is advantageous for pulmonary drug delivery because it alleviates the dependence of delivered doses with the breathing pattern of the patient. ${ }^{8}$ The elevated deep lung deposition of our powders in vitro partly resulted from their low densities, which led to small primary aerodynamic diameters as well as to a large fraction of particle aggregates with an aerodynamic size $\leq 5 \mu \mathrm{m}$.

Powder $\mathrm{A}^{\prime}$ exhibited higher emitted doses and fine particle fractions, smaller MMADs, as well as smaller variations in aerosol characteristics with airflow rate than powder $\mathrm{B}$ (Fig. 1). The higher protein content of powder $\mathrm{A}^{\prime}$ over B might explain their improved flowability and aerosolization properties, as has been proposed previously. ${ }^{10}$ The surfactant properties of proteins likely added to those of DPPC to decrease particle surface energy. Proteins also cause toroidal and indented surface geometries that might limit point-to-point contacts between particles. ${ }^{10,34}$

In conclusion, we showed that the intratracheal administration of an optimized powder aerosol of PTH resulted in high systemic bioavailability in rats. The principal novelty of our study consisted in the demonstration of unexpected physical interactions between drug and excipients that caused significant decrease in systemic absorption.

\section{ACKNOWLEDGMENTS}

The authors thank Renilde Sibenaler and the Laboratoires SMB for providing technical assistance and equipment in HPLC and mass spectrometry, Jacques Adline and the Pharmaceutical 
Chemistry and Radiopharmacy Unit (School of Pharmacy, Université catholique de Louvain) for technical assistance in radioactivity utilization and counting, and Henryk Taper for examination of histological sections. Valérie Codrons is supported by a FIRST Doctorat Entreprise grant 991/ 4160 subsidized by the Walloon Region (Belgium) and SMB-Technology. Rita Vanbever is Chercheur Qualifié of the Fonds National de la Recherche Scientifique (FNRS, Belgium).

\section{REFERENCES}

1. Morley P, Whitfield JF, Willick GE. 2001. Parathyroid hormone: An anabolic treatment for osteoporosis. Curr Pharm Des 7(8):671-687.

2. Neer RM, Arnaud CD, Zanchetta JR, Prince R, Gaich GA, Reginster JY, Hodsman AB, Eriksen EF, Ish-Shalom S, Genant HK, Wang O, Mitlak BH. 2001. Effect of parathyroid hormone (1-34) on fractures and bone mineral density in postmenopausal women with osteoporosis. N Engl J Med 344(19): 1434-1441.

3. Leone-Bay A, Sato M, Paton D, Hunt AH, Sarubbi D, Carozza M, Chou J, McDonough J, Baughman RA. 2001. Oral delivery of biologically active parathyroid hormone. Pharm Res 18(7):964970.

4. Patton JS, Trinchero P, Platz RM. 1994. Bioavailability of pulmonary delivered peptides and proteins: $\alpha$-Interferon, calcitonins and parathyroid hormones. J Control Release 28:79-85.

5. Wolff RK, Allen DL, Hughes BL, Smith HW, Chou JZ, Bowsher RR, Francis PC, Vahle JL. 2000. The case for route-dependent toxicology comparisons: Using large animal models to speed clinical development of inhaled proteins. Respir Drug Deliv VII:163-170.

6. Adjei AL, Gupta PK, editors. 1997. Inhalation delivery of therapeutic peptides and proteins. New York: Marcel Dekker.

7. Timsina MP, Martin GP, Marriott C, Ganderton D, Yianneskis M. 1994. Drug delivery to the respiratory tract using dry powders inhalers. Int J Pharm 101:1-13.

8. Niven R, editor. 1997. Dry powder formulations for inhalation. Adv Drug Deliv Rev (special issue) 26: $1-67$.

9. Vanbever R, Mintzes JD, Wang J, Nice J, Chen D, Batycky R, Langer R, Edwards DA. 1999. Formulation and physical characterization of large porous particles for inhalation. Pharm Res 16(11):17351742.

10. Bosquillon C, Lombry C, Préat V, Vanbever R. 2001. Influence of formulation excipients and physical characteristics of inhalation dry powders on their aerosolization performance. J Control Release 70:329-339.

11. Bosquillon C, Lombry C, Préat V, Vanbever R. 2001. Comparison of particle sizing techniques in case of inhalation dry powders. J Pharm Sci 90:20322041.

12. Méthodes de pharmacotechnie. 1996. In: Pharmacopée Européenne, 3rd ed. Strasbourg, pp 141-142.

13. Hinds WC. 1999. Uniform particle motion. In: Hinds WC, editor. Aerosol technology: Properties, behavior, and measurement of airborne particles, 2nd ed. New York: John Wiley \& Sons, pp 42-74.

14. Préparations pour inhalation: Evaluation aérodynamique des particules fines-Dose des particules fines et distribution granulométrique des particules. Addendum 2001. In: Pharmacopée Européenne, 3rd ed. Strasbourg, pp 115-126.

15. Daugaard H, Egfjord M, Lewin E, Olgaard K. 1994. Metabolism of $\mathrm{N}$-terminal and C-terminal parathyroid hormone fragments by isolated perfused rat kidney and liver. Endocrinology 134(3):1373-1381.

16. Hand JC, Liu P, Dinh SM. 1999. Physical characterization of human parathyroid hormone 1-34, PTH(1-34), in solution. AAPS Pharm Sci 1(4):S558.

17. Hock D, Mägerlein M, Heine G, Ochlich PP, Forssmann W-G. 1997. Isolation and characterization of the bioactive circulating human parathyroid hormone, hPTH-1-37. FEBS Lett 400:221-225.

18. Rowland M, Tozer TN. 1995. Absorption and disposition kinetics. In: Rowland M, Tozer TN, editors. Clinical pharmacokinetics: Concepts and applications, 3rd ed. Baltimore: Lippincott Williams \& Wilkins, pp 11-52.

19. Seibel MW, Lade DA, Hartke JR, Wehmeyer KR. 1996. Validation and application of an immunoradiometric assay for the determination of human parathyroid hormone fragment 1-34 in dog plasma following subcutaneous and intravenous administration. J Pharm Biomed Anal 14:1699-1707.

20. Giacomini KM, Wong FM, Tozer TN. 1984. Correction for volume shift during equilibrium dialysis by measurement of protein concentration. Pharm Res 4:179-181.

21. Henderson RF. 1995. Biological markers in the respiratory tract. In: McClellan RO, Henderson RF, editors. Concepts in inhalation toxicology, 2nd ed. New York: Taylor \& Francis, pp 441-470.

22. Andya JD, Maa YF, Costantino HR, Nguyen PA, Dasovich N, Sweeney TD, Hsu CC, Shire SJ. 1999. The effect of formulation excipients on protein stability and aerosol performance of spray-dried powders of a recombinant humanized anti-IgE monoclonal antibody. Pharm Res 16(3):350-358.

23. Fox J, Miller MA, Stroup GB, Nemeth EF, Miller SC. 1997. Plasma levels of parathyroid hormone that induce anabolic effects in bone of ovariectomized rats can be achieved by stimulation of endogenous hormone secretion. Bone 21(2):163-169. 
24. Claessens P, editor. 2001. Compendium, 19th ed. Brussels: Association Générale de l'Industrie et du Médicament.

25. Lin JH. 1998. Applications and limitations of interspecies scaling and in vitro extrapolation in pharmacokinetics. Drug Metab Dispos 26(12):1202-1212.

26. Sinko PJ, Smith CL, McWhorter LT, Stern W, Wagner E, Gilligan JP. 1995. Utility of pharmacodynamic measures for assessing the oral bioavailability of peptides. I. Administration of recombinant salmon calcitonin in rats. J Pharm Sci 84(11):1374-1378.

27. Uzawa T, Hori M, Ejiri S, Ozawa H. 1995. Comparison of the effects of intermittent and continuous administration of human parathyroid hormone (1-34) on rat bone. Bone 16(4):477-484.

28. Lin JH, Cocchetto DM, Duggan DE. 1987. Protein binding as a primary determinant of the clinical pharmacokinetic properties of non-steroidal anti-inflammatory drugs. Clin Pharmacokinet 12:402-432.

29. Lindup WE. 1987. Plasma protein binding of drugs: Some basic and clinical aspects. In: Bridges JW, Chasseaud LF, Gibson GG, editors. Progress in drug metabolism, Vol. 10. New York: Taylor \& Francis, pp 141-185.
30. Bondanelli M, Margutti A, Ambrosio MR, Plaino L, Cobellis L, Petraglia F, degli Uberti EC. 2001. Blood growth hormone-binding protein levels in premenopausal and postmenopausal women: Roles of body weight and estrogen levels. J Clin Endocrinol Metab 86(5):1973-1980.

31. Brunner F, Stessel H, Watzinger N, Löffler BM, Opie LH. 1995. Binding of endothelin to plasma proteins and tissue receptors: Effects on endothelin determination, vasoactivity, and tissue kinetics. FEBS Lett 373:97-101.

32. Kent GN, Loveridge N, Reeve J, Zanelli JM. 1985. Pharmacokinetics of synthetic human parathyroid hormone 1-34 in man measured by cytochemical bioassay and radioimmunoassay. Clin Sci 68:171177.

33. Zeng XM, Martin GP, Marriot C. 1994. Albumin microspheres as a means of drug delivery to the lung: Analysis of the effects of process variables on particle sizes using factorial design methodology. Int J Pharm 107:205-210.

34. French DL, Edwards DA, Niven RW. 1996. The influence of formulation on emission, deaggregation and deposition of dry powders for inhalation. J Aerosol Sci 27:769-783. 